Historia

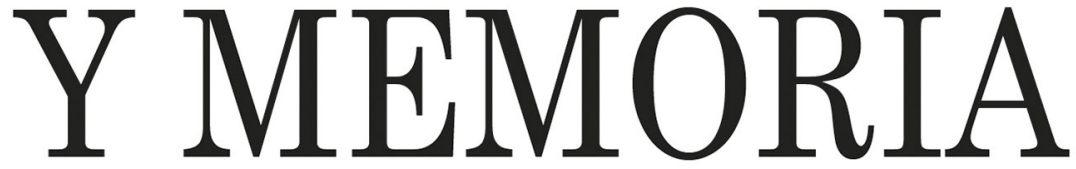

ISSN: 2027-5137 Julio - Diciembre, Año 2016 - Tunja, Colombia

\title{
La Estrella del Tolima, 1882-1884. El último aliento del liberalismo radical en Neiva
}

Jean Paul Ruiz Martinez y Cristian Salamanca Arévalo Páginas: 215 - 256 DOI: http://dx.doi.org/10.19053/20275137.5205

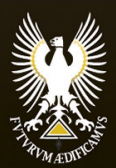




\title{
La Estrella del Tolima, 1882-1884. El último aliento del liberalismo radical en Neiva*
}

\author{
Jean Paul Ruíz Martínez ${ }^{1}$ \\ Universidad Nacional de Colombia \\ Cristian Salamanca Arévalo ${ }^{2}$ \\ Universidad del Tolima - Colombia
}

Recepción: 15/11/2015

Evaluación: 29/04/2016

Aprobación: 16/05/2016

Artículo de Investigación e Innovación.

DOI: http://dx.doi.org/10.19053/20275137.5205

\section{Resumen}

En este texto se estudia La Estrella del Tolima, publicación radical editada en Neiva entre 1882 y 1884, en un contexto de fragmentación del liberalismo y ascenso del sector independiente. Para tal fin, prestamos atención a la división del Partido Liberal y la situación de su facción radical, para

\footnotetext{
* Este artículo hace parte de los resultados de la beca del Programa Nacional de Estímulos, "Sobre prensa regional: compilación y fichas catalográficas de la prensa del Tolima, siglo XIX», otorgada por la Biblioteca Nacional de Colombia y el Ministerio de Cultura, mediante resolución 1558 de 2012. [Agradecemos a Sergio Mejía Macía y Adriana Díaz por las correcciones y comentarios a nuestro texto, los cuales ayudaron a definir la forma de abordar La Estrella del Tolima. También queremos agradecer de manera especial a Bernardo Tovar Zambrano].

1 Historiador y estudiante de la Maestría en Historia de la Universidad Nacional de Colombia, institución en la cual es asistente docente de la Dirección Académica para el área de historia colonial. Actualmente se interesa por la historia de la prensa, la imprenta y la historia política. Correo electrónico: jeanpaulruiz@gmail.com

2 Historiador y estudiante de la Maestría en Historia de la Universidad Nacional de Colombia. Profesor catedrático del programa de Historia de la Universidad del Tolima e integrante del grupo de investigación Hechos. Historia económica y social de la misma institución. Actualmente se encuentra interesado en la historia de la prensa, la imprenta y la historia política. Correo electrónico: cristian.gsa@gmail.com
} 
luego estudiar la postura y estrategia que propusieron los radicales desde La Estrella para sobrevivir como fuerza política en la escena nacional y mantener el control del gobierno del Estado Soberano del Tolima. Metodológicamente, el artículo deriva de la compilación y análisis de la prensa decimonónica del Tolima Grande, junto con la exploración de folletería y memorias de la región, con el fin de analizar a La Estrella en el universo editorial tolimense y de captar su importancia para la política de la época. Con este estudio se postula que La Estrella se consolidó como la última tribuna de defensa y opinión del radicalismo en el Tolima, por las relaciones que los radicales detrás del periódico guardaban con el gobierno y por su permanencia política en el Estado hasta 1884.

Palabras clave: Estrella del Tolima, liberalismo radical, liberalismo independiente, nuñismo, Estado Soberano del Tolima, prensa.

\title{
La Estrella del Tolima Newspaper, 1882-1884. The Last Breath of Radical Liberalism in Neiva
}

\begin{abstract}
This study examines La Estrella del Tolima, a radical newspaper edited in Neiva between 1882 and 1884, in the context of the fragmentation of liberalism and the rise of the independent sector. In order to do this, we focus on the division of the Liberal Party and the situation of its radical faction. Afterwards, we explore the position and strategy proposed by the radicals, by means of La Estrella, in order to survive as a political power in the national scene and maintain control of the government in the Sovereign State of Tolima. Methodologically, the article derives in the compilation and analysis of the decimononical press of the Great Tolima region; together with a study of the pamphlets and memoirs of the region, enabling an analysis of La Estrella in the context of the editorial universe of Tolima, that captures its importance for the politics of the time. This study postulates that La Estrella consolidated the last tribune of radical opinion and defense in
\end{abstract}


the State of Tolima, due to the relations between the radicals who ran the newspaper and the government, as well as their political permanence in the State until 1884.

Key words: Estrella del Tolima newspaper, liberalism, radical, independent liberalism, nuñismo, Sovereign State of Tolima, press.

\section{La Estrella del Tolima, 1882-1884. Le dernier souffle du libéralisme radical à Neiva}

\section{Résumé}

Dans ce texte on étudie l'Estrella del Tolima, un journal radical publiée à Neiva entre 1882 et 1884, dans un contexte de fragmentation du libéralisme et de montée en puissance du secteur indépendant. Pour cela, nous analysons dans un premier temps la division du Parti Libéral et la situation de la faction radicale. Ensuite nous étudions la stratégie développée par les radicaux depuis l'Estrella pour survivre en tant que force politique dans la scène nationale et pour maintenir le contrôle de l'État Souverain du Tolima. Les sources dont nous nous sommes servi pour écrire cet article sont la presse, les brochures et les mémoires rédigées dans la région, ce qui permet de mettre en rapport l'Estrella avec l'univers éditorial du Tolima et de saisir l'importance dudit journal dans la politique de l'époque. Avec cette étude nous nous proposons de montrer que l'Estrella constitue la dernière forteresse du radicalisme dans l'Etat du Tolima, en raison des liens que les radicaux engagés dans la publication ont entretenus avec le gouvernement.

Mots-clés: La Estrella del Tolima, libéralisme radical, libéralisme indépendant, nuñismo, État Souverain du Tolima, presse. 


\section{Introducción}

Estudiar una publicación seriada editada en vísperas de la Guerra Civil de 1885, la Constitución Política de 1886 y la firma del Concordato en 1887, implica analizar un escenario privilegiado en tiempos de restructuración política. La Estrella del Tolima, publicación radical editada en Neiva entre 1882 y 1884, circuló en ese contexto, y para ser precisos, entre las guerras civiles de $1876-1877^{3}$ y la de 1885 . Un momento que sobresale en la historia del liberalismo decimonónico, por ser un espacio de discusiones políticas que permiten evidenciar la manera en que el liberalismo pasa de ser una fuerza política dominante, a un partido dividido que pierde su hegemonía en la política federal ${ }^{4}$.

Desde La Estrella del Tolima (en adelante La Estrella) los radicales del Tolima, reunidos en su capital Neiva, escribieron en favor de la unidad liberal. Ya que el debilitamiento del liberalismo no había surgido por el fortalecimiento de su rival, el partido conservador, sino por el ascenso paulatino del liberalismo independiente. Así pues, en las páginas del periódico puede leerse el último esfuerzo de los radicales tolimenses por lograr la unidad del partido y garantizar su continuidad en el poder.

Estudiar La Estrella tiene dos particularidades historiográficas, a saber: por un lado, el rescate de un

3 Sobre la guerra civil de 1876-1877 ver los trabajos de Luis Javier Ortiz Mesa: Ganarse el cielo defendiendo la religión guerras civiles en Colombia, 1840-1902, (Medellín: Universidad Nacional de Colombia, 2005); y «los radicales y la guerra civil de 1876-1877», en El radicalismo colombiano del siglo XIX, ed. Rubén Sierra Mejía. (Bogotá: Universidad Nacional de Colombia, 2006): 221-251. También ver: Hugo Andrés Arenas Mendoza, ¿Estado irresponsable o responsable? La responsabilidad patrimonial del Estado colombiano, luego de la Guerra Civil de 1876-1877 (Bogotá, Editorial Universidad del Rosario, 2008).

4 El faccionalismo del Partido Liberal y la pérdida de su hegemonía política ha sido estudiado en: James W. Park, Rafael Núñez and the Politics of Colombian Regionalism, (Baton Rouge: University of Louisiana Press, 1985); Helen Delpar, Rojos contra azules. El Partido liberal en la política colombiana 1863-1899, (Bogotá: Procultura, 1994); Lázaro Mejía Arango, Los Radicales. Historia política del radicalismo del siglo XIX, (Bogotá: Universidad Externado de Colombia, 2007) y Antonio Pérez Aguirre, Los radicales y la Regeneración, (Bogotá: Cromos, 1941). 
periódico sumamente relevante para la política decimonónica tolimense, olvidado por el precario desarrollo de la historia de la prensa de la región; y por otro, el análisis de la política liberal en perspectiva regional, útil para profundizar sobre la polarización y fragmentación política del liberalismo colombiano. En ese orden, la lectura de La Estrella nos permite dimensionar su relevancia dentro de la prensa de Neiva, analizar los argumentos a favor de la unidad liberal entre 1882 y 1884, y estudiar la división liberal que antecedió la reforma política que hoy conocemos como La Regeneración.

Desde esta perspectiva esperamos contribuir con: la historia de la prensa, la historia política y la historia regional. Para tal fin, empezamos con un contexto político del liberalismo decimonónico; continuamos con un comentario sobre los estudios de la prensa del Tolima Grande; procedemos a la descripción y análisis de La Estrella, para seguir con el análisis la coyuntura política de 1882 y 1884 vista desde el periódico. Terminamos con algunas consideraciones sobre el trabajo.

\section{Ascenso y crisis del liberalismo radical en los Estados Unidos de Colombia}

Helen Delpar define al Partido Liberal del siglo XIX como un "agregado de grupos locales y regionales que podían unirse en momentos críticos" Liberal se asociaba a un conjunto de ideas y líderes que tenían dominio sobre un grupo de seguidores, este partido, añade Delpar, no contó con una estructura en el sentido moderno y fue proclive a la división ${ }^{6}$. Este fenómeno fue estudiado por James Park, quien lo explica en razón de diferencias ideológicas y regionales. Según Park, a mediados de siglo el Partido Liberal se dividió por diferencias ideológicas entre radicales (gólgotas) y moderados (draconianos) ${ }^{7}$. Una vez los radicales consiguieron el control del gobierno nacional en 1867, se hizo evidente que este sector favorecía a los tres

5 Delpar, Rojos contra azules, 4.

6 Delpar, Rojos contra azules, xxxv.

7 Park, Rafael Núñez and the Politics, 49. 
estados de las montañas orientales (Santander, Boyacá y Cundinamarca). El argumento de la discriminación regional y el deseo de terminar la hegemonía radical aparentemente profundizaron las fisuras en el Partido Liberal con mayor fuerza que las diferencias ideológicas.

La campaña presidencial de 1875 en la que Aquileo Parra y Rafael Núñez compitieron por la presidencia reveló las características de esta división ${ }^{8}$. La candidatura de Núñez, fue presentada por nueve liberales de los estados de la costa (Bolívar, Magdalena y Panamá) durante una convención que se desarrolló en enero de 1875 en Barranquilla ${ }^{9}$. Y contó con el apoyo de Mosquera y los mosqueristas, de liberales cercanos a las administraciones radicales (Salvador Camacho Roldán, Carlos Martín, Teodoro Valenzuela, entre otros) e incluso de expresidentes de la Unión como Santos Acosta y Eustorgio Salgar $^{10}$. El ambiente de las elecciones, anormal y violento ${ }^{11}$, caracterizado por las acusaciones y presiones de uno y otro bando, dejó como resultado unas votaciones divididas: Parra con 4 votos (Boyacá, Cundinamarca, Santander y Magdalena), Núñez con 2 votos (Panamá y Bolívar), Bartolomé Calvo (conservador) con 2 votos (Antioquia y Tolima), y la abstinencia del Cauca que no votó. Como ninguno de los candidatos obtuvo cinco votos, el Congreso decidió el 21 de febrero de 1876 en favor de Parra.

Aunque la candidatura de Núñez inició como una reivindicación de los liberales de los estados costeros, es preciso aclarar que la rivalidad entre los dirigentes de Bolívar y Magdalena fue un inconveniente para que Magdalena respaldara a Núñez. Por otra parte, los estados gobernados por conservadores (Antioquia y Tolima) aunque tuvieron acercamientos con Núñez, votaron por Bartolomé Calvo para

8 Park, Rafael Núñez and the Politics, 140.

9 Delpar, Rojos contra azules, 246.

10 Delpar, Rojos contra azules, 248.

11 Delpar, Rojos contra azules, 261. 
no oponerse a los radicales con quienes tenían acuerdos ${ }^{12}$. Con la victoria de Parra, los radicales consiguieron mantener la presidencia del país y encabezaron la unión liberal que logró la victoria frente a la revolución conservadora del Cauca entre 1876-1877. Además, el triunfo electoral permitió que se llevara a cabo un desplazamiento en los gobiernos conservadores de Antioquia y Tolima, y su posterior reemplazo por mandatos radicales.

Aunque los conservadores fueron derrotados militarmente nunca desaparecieron del mapa político, lo que se vivió fue una reorientación de sus formas de hacer política: pasaron a tener una orientación nacional por encima de la regional, más centralista que federalista y más secular que religiosa ${ }^{13}$, entendieron su debilidad militar, abandonaron la estrategia bélica, y fortalecieron la colaboración con los liberales no radicales, con lo cual favorecieron el faccionalismo liberal. Bajo estas condiciones, Núñez ejerció la presidencia del Estado de Bolívar en $1877^{14}$, mientras que los ocho estados restantes eran gobernados por radicales. Sin embargo, lejos de estar aislado políticamente, Núñez representaba el descontento con la hegemonía radical, el cual comenzó a conocerse como liberalismo independiente dentro de las facciones radicales ${ }^{15}$.

Los independientes constituidos como una facción diferente al radicalismo, promovieron y defendieron la idea de la unión liberal, la cual se vio respaldada por la elección de Julián Trujillo Largacha como presidente de los Estados Unidos de Colombia en 1878 (con un respaldo total en las urnas, 9 votos). La administración de Trujillo se caracterizó por la inclusión de los independientes dentro de las secretarías

12 En 1873 Julián Trujillo, liberal, consiguió el apoyo de los conservadores en ambos estados en el marco de las alianzas entre mosqueristas y conservadores para debilitar a los radicales.

13 Park, Rafael Núñez and the Politics, 179.

14 Lo fue durante el periodo 1876-1879.

15 Park, Rafael Núñez and the Politics, 186-187. 
de la administración estatal ${ }^{16}$. Los radicales de la época vieron la iniciativa de Trujillo como una traición. En ese contexto, las siguientes elecciones presidenciales, nuevamente disputadas entre Parra y Núñez, se caracterizaron por la división del liberalismo y la oposición de los radicales a Núñez y sus aspiraciones presidenciales.

El gobierno de Trujillo buscó enfrentar la crisis que se vivía en el país con un programa diferente al radical ${ }^{17}$. El cambio de gobierno en los estados se debió a diferentes factores: la alianza entre independientes y conservadores, el aprovechamiento de la unión liberal durante la guerra, la permisividad del gobierno central y el debilitamiento del liberalismo radical como alternativa a la crisis de estados como el Cauca. Este cambio administrativo, originado por diferentes causas en cada Estado, marcó el inicio de un panorama político donde la facción radical, apenas sobrevivía y sus partidarios esgrimían discursos y programas para impedir su desaparición ${ }^{18}$.

Solo en Antioquia y Tolima los radicales consiguieron mantener el control de los estados a pesar de los intentos de los independientes por desplazarlos. Tomás Rengifo en Antioquia consiguió soportar motines y vencer en la guerra de 1879, declarada al interior por los independientes aliados con conservadores. Mientras, en el Tolima Neiva se había convertido en un enclave del liberalismo radical, retomando el pasado liberal de la parte sur del Estado. En 1879 cuando el radical Fruto Santos fue elegido como presidente del Estado, Didacio Delgado con el apoyo de los independientes emprendió una campaña militar que salió de Cundinamarca para el

16 En el primer grupo de secretarios solamente dejó participar a liberales independientes: Francisco Javier Zaldúa (secretario de lo Interior y Relaciones Exteriores), Rafael Núñez (secretario de Hacienda y Fomento), Salvador Camacho Roldán (secretario del Tesoro y Crédito Nacional), y Ezequiel Hurtado (secretario de Guerra y Marina).

17 Mejía, Los Radicales, 513-528.

18 Para un estudio detallado del relevo político en los estados, de radicales a independientes, ver: Park, Rafael Núñez and the Politics. 
Tolima, pero que no trascendió al no encontrar el apoyo de los habitantes del Tolima.

Al iniciar 1880 los liberales radicales habían perdido su fuerza en 7 de los 9 estados y, paradójicamente, conservaban el gobierno en los dos que fueron gobernados por conservadores en 1876. La transferencia de poder que empezó durante el gobierno de Trujillo estaba terminada ${ }^{19}$, tal y como demostró la victoria de Núñez en las elecciones de 1879 al obtener 7 votos de los 9 posibles ${ }^{20}$. Con este cambio en la política nacional, en el que el liberalismo transitaba por un camino que llevaba a su desintegración, apareció en la arena editorial de Neiva $L a$ Estrella con el objetivo de promover la cohesión del partido liberal tan afectado por las transformaciones mencionadas.

\section{La Estrella del Tolima en la historiografía}

Ubicar historiográficamente La Estrella nos remite el análisis de la historia de la prensa a nivel nacional y regional. En las obras generales sobre la historia del periodismo en Colombia de Gustavo Otero Muñoz ${ }^{21}$ y Antonio Cacua Prada ${ }^{22}$, no hay referencia al periódico estudiado. Sin embargo, en el Catálogo publicaciones seriadas siglo XIX se enlistan los periódicos publicados en Neiva, que se conservan en la Biblioteca Nacional de Colombia (BNC) entre los que se relaciona $L a$ Estrella y su editor Alejandro Rojas ${ }^{23}$.

En su libro La imprenta en Colombia, Tarsicio Higuera analiza el desarrollo de la imprenta en las diferentes ciudades del país e incluye un listado de los periódicos editados en cada

19 Park, Rafael Núñez and the Politics, 235.

20 Tolima y Antioquia votaron por Tomás Rengifo.

21 Gustavo Otero Muñoz, Historia del periodismo en Colombia, (Bogotá: Universidad Sergio Arboleda, 1998).

22 Antonio Cacua Prada, Historia del periodismo colombiano, (Bogotá: Fondo Rotatorio Policía Nacional, 1968).

23 Biblioteca Nacional de Colombia, Catálogo publicaciones seriadas siglo XIX, t 2., (Bogotá: Biblioteca Nacional de Colombia / Instituto Colombiano de Cultura, 1995), 493. 
una $^{24}$. Higuera afirma no haber encontrado mayor información sobre el funcionamiento de la imprenta en Neiva, salvo que en 1884 Alejandro Rojas firmaba el pie de imprenta del Registro Oficial del Estado del Tolima y actuaba como su editor. En su inventario Higuera relaciona La Estrella como una publicación de $1884^{25}$, hoy sabemos que se editó entre 1882 y 1884 .

No existe un estudio general sobre la prensa del Estado Soberano del Tolima. Sin embargo, Agustín Angarita Somoza en Historia del periodismo en el Tolima se propuso presentar un listado de las publicaciones editadas en el Tolima Grande, desde el siglo XIX hasta 1970 e incluir a Neiva, Garzón y El Gigante. Según el autor, el trabajo no pudo ser realizado debido a un incendio en la Imprenta Departamental de Neiva y como consecuencia el libro únicamente relaciona las publicaciones del actual departamento del Tolima ${ }^{26}$. Así pues, los trabajos que encontramos sobre la prensa del Tolima se han preocupado por algunas de sus capitales, particularmente Ibagué y Neiva ${ }^{27}$.

Algunos de los trabajos sobre la prensa decimonónica neivana reproducen los datos que se encuentran en el Catálogo de todos los periódicos que existen desde su fundación hasta el año de 1935 editado por la $\mathrm{BNC}^{28}$, y en el libro de Cien años de prensa en Colombia 1840-1940. Catálogo indizado de la prensa existente en la Sala de Periódicos de la Biblioteca Central de la Universidad de Antioquia ${ }^{29}$. Nos referimos a Delimiro

24 Tarciso Higuera, La imprenta en Colombia (Bogotá, Inalpro, 1970).

25 Higuera, La imprenta en Colombia, 221.

26 Agustín Angarita Somoza, Historia del periodismo en el Tolima, t. 1, (Ibagué: Editorial Tolima, 1970).

27 Para una descripción sobre la prensa editada en la ciudad de Ibagué se puede consultar: Magdalena Santamaría Granda, Historia y desarrollo de la prensa en Ibagué, (Bogotá, 2001); Camilo Pérez Salamanca, «Historia del Periodismo», en Manual de Historia del Tolima, t.3, de Carlos Orlando Pardo Rodríguez, et al., (Ibagué: Pijao Editores, 2007), 360-393.

28 Biblioteca Nacional de Colombia, Catálogo de todos los periódicos que existen desde su fundación hasta el año de 1935, t.2, (Bogotá: Editorial El Gráfico, 1936).

29 Jesús María Álvarez Gaviria y María Teresa Uribe de Hincapié, Cien años de prensa en Colombia 1840-1940. Catálogo indizado de la prensa existente en la Sala 
Moreno en su trabajo "Periódicos huilenses 1840-1890"30 y a Reynel Salas Vargas en "Relación de periódicos editados en el departamento del Huila, existentes en la Hemeroteca Manuel del Socorro Rodríguez de la Biblioteca Nacional ${ }^{31}$. Ambos trabajos solo hacen inventarios de los periódicos neivanos conservados en los repositorios de la Universidad de Antioquia (UdeA) o la BNC.

Por su parte, Francisco Sánchez Ramírez, en "Periodismo en el Huila" presenta apuntamientos sobre la imprenta en Neiva, y de los periodistas y publicaciones del departamento de Huila. Su trabajo incluye La Estrella y establece su periodo de edición entre 1882-1884 ${ }^{32}$. De otro lado, Camilo Francisco Salas Ortiz se ha ocupado del periodismo en el Huila en Historia del periodismo huilense. La prensa escrita y en "Trayectoria del periodismo huilense" ${ }^{33}$. Salas describe las publicaciones huilenses, sus características editoriales y en algunos casos señala sus tendencias políticas. Sobre La Estrella se limita a retomar la información que Delimiro Moreno reprodujo del libro Cien años de prensa en Colombia. Diferente método adopta Álvaro Trilleras Roa, aunque equivocado, cuando afirma en Del linotipo al satélite que La Estrella era propiedad de Francisco Javier Zaldúa ${ }^{34}$. En el periódico aparece la figura de Zaldúa como un candidato presidencial al que se apoyaba, pero no, y es preciso ser enfáticos en ello, como la del propietario del periódico.

de Periódicos de la Biblioteca Central de la Universidad de Antioquia, (Medellín, Editorial Universidad de Antioquia, 2002).

30 Delimiro Moreno, «Periódicos Huilenses», Huila. Órgano de la Academia Huilense de Historia, $\mathrm{n}^{\circ} 31$ (1984): 75-79.

31 Reynel Salas Vargas, "Relación de periódicos editados en el departamento del Huila. Existentes en la Hemeroteca Manuel del Socorro Rodríguez de la Biblioteca Nacional», Huila. Órgano de la Academia Huilense de Historia, nº 37 (1987): 85-87.

32 Francisco Sánchez Ramírez, «Periodismo en el Huila», Huila. Órgano de la Academia Huilense de Historia, $\mathrm{n}^{\circ} 31$ (1984): 68-74.

33 Camilo Francisco Salas Ortiz, Historia del periodismo huilense: la prensa escrita, (Neiva: Instituto huilense de cultura, 1994); y «Trayectoria del periodismo huilense», en Historia general de Huila, t. 3, dir. Bernardo Tovar Zambrano. (Neiva: Instituto Huilense de Cultura/ Fondo de Autores Huilenses/ Gobernación del dpto. del Huila/ Academia Huilense, 2005): 97-146.

34 Álvaro Trilleras Roa, Del linotipo al satélite. Los medios de comunicación y el periodismo en el Huila, (Neiva: Impresos Litosol, 2005), 18. 
Podemos inferir que solo Álvarez Gaviria y Uribe de Hincapié han aportado información precisa sobre La Estrella, y que su obra ha sido la guía de todos aquellos interesados en la prensa decimonónica neivana. Aunque Cien años de prensa en Colombia es un catálogo y no incluye un análisis detallado de La Estrella, recoge información importante sobre su contenido, entre ella: que fue una publicación semanal de tendencia radical, que polemizaba con $L a L u z$ de Bogotá y que defendió las candidaturas para la presidencia federal de José Eusebio Otálora y de Solón Wilches ${ }^{35}$.

Observamos que existe un vacío de conocimiento sobre la prensa editada en el Estado Soberano del Tolima y la ciudad de Neiva. Por nuestra parte, contribuimos con un artículo titulado "Prensa decimonónica de la ciudad de Neiva. Apuntes para su historia", en el que presentamos una relación de las publicaciones seriadas de la ciudad, acompañada de comentarios sobre sus contenidos y temas ${ }^{36}$. En esas condiciones, esperamos realizar un aporte historiográfico doble: por un lado, contribuir con la historia de la prensa de Neiva y del Estado Soberano del Tolima mediante el estudio de uno de sus periódicos de mayor duración; y por el otro, esclarecer un momento trascendental de la historia política colombiana con atención a un caso regional. En este orden, La Estrella se presenta como una ventana para mirar desde el Tolima el ocaso del liberalismo del siglo XIX, luego de $\mathrm{su}$ fraccionamiento entre radicales e independientes como antesala a La Regeneración.

\section{La Estrella del Tolima (Neiva, 1882-1884)}

La Estrella se publicó en Neiva en la década de 1880, el periodo de mayor afluencia de periódicos en la ciudad durante el siglo

35 Álvarez Gaviria y Uribe de Hincapié, Cien años de prensa en Colombia, 131.

36 En esa década se publicaron 19 de los 30 periódicos que circularon entre 1850 y 1900. Jean Paul Ruíz Martínez y Cristian Salamanca Arévalo, «Prensa decimonónica de la ciudad de Neiva. Apuntes para su historia», en Historia Comprehensiva de Neiva, t.2, dir. Bernardo Tovar Zambrano (Neiva: Alcaldía de Neiva / Academia huilense de historia / Secretaría municipal de cultura y turismo, 2013), 411-443. 
$\mathrm{XIX}^{37}$. La prensa de entonces insistía en varios temas, a saber: el progreso económico y comercial del Estado Soberano del Tolima, la organización administrativa del mismo en sus diferentes departamentos y el ordenamiento de la Diócesis del Tolima $^{38}$. Sin embargo, hay un tema que sobresale en la prensa neivana por su dinamismo y recurrencia: la desintegración del Partido Liberal y la búsqueda de su cohesión luego de la guerra civil de 1876-1877.

Estetema apareceen publicaciones comoElElector (1883), El Bien Público (1883) y El Alto Magdalena (1884), desde las que se promovía y defendía la integración del liberalismo, bien fuera desde el sector radical o el independiente. Sin embargo, solo en La Estrella se consolida una tribuna de la opinión radical tolimense que guardaba vínculos con el gobierno del Tolima y que, a diferencia de otros periódicos, sobrevivió a las elecciones presidenciales del Estado Soberano. Motivo por el cual proponemos y pretendemos demostrar que La Estrella se consolidó y presentó como el baluarte del radicalismo tolimense y su publicación más representativa.

El primer número de La Estrella se publicó el 6 de mayo de 1882 y el último que se conserva el 7 de diciembre de 1884 (núm. 103). Su periodicidad fue semanal aunque tuvo interrupciones, y su propietario y director fue Alejandro Rojas. La figura de Rojas es recurrente en la prensa neivana al aparecer como editor o encargado de la publicación de

37 En esa década se publicaron 19 de los 30 periódicos que circularon entre 1850 y 1900. Los 30 periódicos publicados en Neiva se calculan mediante el cruce de las existencias conservadas en la Universidad de Antioquia (UdeA), la Biblioteca Luis Ángel Arango (Blaa) y la Biblioteca Nacional de Colombia (BNC). La compilación de estos periódicos y de todos los publicados en el Tolima durante el siglo XIX se pueden consultar en: "Colección de prensa del Tolima siglo XIX», en Biblioteca digital. Prensa siglo XIX, Jean Paul Ruíz Martínez y Cristian Salamanca Arévalo, investigadores, (Bogotá: Biblioteca Nacional de Colombia, 2012), disponible en: http://www. bibliotecanacional.gov.co/content/prensa-tolimense-del-siglo-xix. La compilación se elaboró con la coordinación de Camilo Páez Jaramillo.

38 Sobre la organización de la Diócesis del Tolima ver: Cristian Salamanca Arévalo, «La iglesia en Neiva. El papel eclesiástico en la organización socio- política durante el siglo XIX», en Historia Comprehensiva de Neiva, t.2., dir. Bernardo Tovar Zambrano (Neiva: Alcaldía de Neiva / Academia huilense de historia / Secretaría municipal de cultura y turismo, 2013): 173-200. 
6 de los 19 periódicos editados en Neiva en la década de $1880^{39}$. Aunque se desconoce el lugar de nacimiento de Rojas, sabemos que era "hijo de otro Estado" 40 . Entre 1882 y 1884 establecemos dos vínculos claves de Rojas con el gobierno del Estado: primero, su vinculación como contratista con la Imprenta del Estado desde 1881 hasta 1884, y segundo, el cargo que desempeñó como presidente de la Corporación Municipal de Neiva en $1883^{41}$. Estos cargos permiten entender la continuidad editorial y su relevancia para el radicalismo en vísperas a la guerra civil de 1885, ya que como editor contó con las garantías y el respaldo del gobierno estatal ${ }^{42}$. En ese orden, no es de extrañar, como lo indicaría Clodomiro Castillo, que La Estrella representó por un momento la idea liberal de retomar las armas ante el ascenso de Núñez ${ }^{43}$.

La labor desempeñada por Alejandro Rojas en la Imprenta del Estado fue ponderada en la Memoria del

39 Los periódicos que fueron editados o impresos por Alejandro Rojas durante la década de 1880 en la ciudad de Neiva son: El Vijilante (1880), La Revista Judicial del Tolima (1880-1884), La Estrella del Tolima (1882-1884), La Crónica Forense (1883), El Elector (1883), El Alto Magdalena (1884) y La Grilla (1884).

40 La Estrella del Tolima, Neiva, 29 de julio de 1882.

41 La vinculación de Alejandro Rojas como presidente de la Corporación Municipal de Neiva se encuentra en el número 62 de La Estrella, en el que también se rinde homenaje necrológico a Miguel María Durán G. La Estrella del Tolima, Neiva, 8 de julio de 1883.

42 Para un estudio sobre el desarrollo de las guerras civiles en Neiva a final del siglo ver: Jean Paul Ruíz Martínez, «Guerra y política en la Neiva decimonónica. Fin de siglo y batalla de Matamundo», en Historia Comprehensiva de Neiva, t.2., dir. Bernardo Tovar Zambrano (Neiva: Alcaldía de Neiva / Academia huilense de historia / Secretaría municipal de cultura y turismo, 2013): 517-536.

43 La denominación de La Estrella del Tolima como un periódico semioficial, se encuentra en la carta de protesta escrita por Clodomiro Castillo a una hoja volante titulada La unión liberal en el Tolima y su programa. En la reclamación de Castillo indica que hubo un momento donde existió la idea de retomar las armas para defender la causa liberal: «la posición oficial del partido liberal que creyeron comprometida por la elevación del doctor Núñez á la Presidencia, es un hecho que está en la conciencia de todos los colombianos cuya imparcialidad no sea tan intermitente y achacosa como la de nuestro acusador; y que el Presidente del Tolima conocía ese propósito y no lo resistía, podemos comprobarlo con la Gaceta Oficial y con La Estrella semioficial, con una hoja suelta, salida de las prensas oficiales, en que se proclamaba la guerra como programa de todo el partido liberal y con el Mensaje del Presidente á la Asamblea». Clodomiro Castillo, Rectificaciones a la hoja titulada «la Unión liberal en el Tolima y su programa», (Bogotá: Imprenta la Luz, 1884),7. Las negrillas son nuestras. 
Secretario de Gobierno del Tolima de 1881, elaborada por Miguel María Durán G., quien recordaba que:

[...] el establecimiento tipográfico de propiedad del Gobierno está en una situación casi de completa ruina, i si no fuera por los gastos particulares hechos por el contratista señor Alejandro Rójas, seria ya imposible que, con los elementos con que hoy cuenta la imprenta, se pudiera hacer publicación alguna $^{44}$.

El secretario, radical y redactor de La Estrella, agregaba: "Una vez cese [su] contrato, lo que tendrá lugar el 31 de diciembre próximo, i que el señor Rojas retire del establecimiento los elementos de su propiedad, traídos recientemente, la Imprenta del Estado quedará, poco menos, que inútil" ${ }^{45}$. En La Estrella colaboraban un grupo de redactores que representaban el núcleo activo del radicalismo en Neiva y que hicieron del periódico su vehículo de lucha política. Entre ellos encontramos a: Miguel María Durán (redactor principal), José Lizardo Porras y Belisario Arciniegas ${ }^{46}$.

Existe un apartado relevante sobre Alejandro Rojas en la Historia del periodismo colombiano de Cacua. El autor afirma que Rojas compró, con el beneplácito de Jacobo Sánchez (gobernador de Cundinamarca), la imprenta donde se publicaba El Tradicionista; el cual, fue editado por Miguel Antonio Caro en Bogotá entre 1871 y 1876 en oposición al gobierno radical de Aquileo Parra ${ }^{47}$. Esta referencia es relevante para esclarecer la procedencia de las máquinas que funcionaban en la Imprenta del Estado del Tolima, de propiedad de Rojas, porque sugiere que existe una relación entre la expropiación de $E l$ Tradicionista y la imprenta que funcionó en Neiva.

44 Memoria que el Secretario de Gobierno del Tolima dirige al presidente del Estado para la Asamblea Legislativa de 1881, (Neiva: Imprenta del Estado, 1881), 97.

45 Memoria que el secretario de gobierno del Tolima, 97.

46 La Estrella del Tolima, Neiva, 20 de mayo de 1883.

47 Cacua, Historia del periodismo colombiano, 74. 
Al estudiar la ley de libertad absoluta de imprenta en los Estados Unidos de Colombia (numeral 6 del artículo 15 de la Constitución Rionegro) Posada Carbó apunta que las confiscaciones, censuras y expropiaciones efectuadas durante el Olimpo Radical contradicen la política liberal de imprenta ${ }^{48}$. Entre los casos más destacados de confiscación se encuentra la expropiación de El Tradicionista.

El 9 de octubre de 1876 el primer cuerpo de policía del Estado Soberano de Cundinamarca, con sede en Bogotá, dictaminó el cobro de 6.000 pesos contra El Tradicionista por medio de un empréstito forzoso ${ }^{49}$. El 18 del mismo mes se realizó el avalúo de los bienes que reposaban en las instalaciones de $E l$ Tradicionista y se relacionó con ellos "una prensa imperial número 5, una número 4, 9 fuentes de tipos de madera, cuadros huecos, marcos de hierro, chibaletes, máquinas de cortar", entre otros bienes cuyo valor ascendía a 6.152 pesos $^{50}$. Luego del avalúo se estableció que el 28 de octubre de ese año, se remataría, junto con la imprenta de El Tradicionista, la de La Ley, propiedad de José María Samper ${ }^{51}$. Al remate de la imprenta, según se establece en la Diligencia de remate ${ }^{52}$, solo se presentó Alejandro Rojas con su fiador Diógenes Arrieta e hicieron una postura por 3.076 pesos, la mitad del precio de avalúo ${ }^{53}$. La propuesta de Rojas fue aprobada y la imprenta de Caro pasó a manos de Rojas, claro está, teniendo como fondo las reclamaciones de Caro quien acusaba al gobierno del abuso infligido a su más sonado

48 Eduardo Posada Carbó, «Libertad, libertinaje, tiranía, 1863-1865», en Construcciones impresas. Panfletos, diarios y revistas en la formación de los estados nacionales en América Latina, 1820-1920, comp. Paula Alonso, (México: Fondo de cultura económica, 2003), 197.

49 «Ejecución contra la imprenta de 'El Tradicionista' por la suma de $\$ 6.000$ que le fue asignada por empréstito forzoso", en El centenario de El Tradicionista. Datos para la biografía de Miguel Antonio Caro, de Carlos Valderrama Andrade (Bogotá: Instituto Caro y Cuervo, 1972), 55.

50 «Ejecución contra la imprenta de 'El Tradicionista'», 63.

51 «Remates para el pago de empréstitos forzosos», en Valderrama, El centenario de El Tradicionista, 67.

52 «Diligencia de remate», en Valderrama, El centenario de El Tradicionista, 70.

53 «Diligencia de remate», en Valderrama, El centenario de El Tradicionista, 70. 
contradictor (El Tradicionista) y reclamaba la devolución de la imprenta, algo que nunca ocurrió ${ }^{54}$.

En respuesta a Caro, Dámaso Zapata, secretario de Gobierno del Estado Soberano de Cundinamarca, elevó una misiva ante el secretario de Hacienda y Fomento, en la que sostuvo que la razón de la expropiación fue la "mala voluntad" que los redactores del periódico imprimían en sus páginas ${ }^{55}$, y que de ninguna manera la imprenta sería destrozada, ya que la persona que la adquirió, Alejandro Rojas, había cedido las máquinas a la imprenta al gobierno de Cundinamarca por el mismo valor del remate. Además, ese gobierno había decidido que las imprentas en su poder fueran adjudicadas a las cabeceras de cada Estado Soberano, según decreto 427 del ejecutivo cundinamarqués.

Este punto resulta relevante para el estudio de la imprenta del Estado Soberano del Tolima, ya que según ese decreto, publicado en el Diario de Cundinamarca el 2 de julio de $1877^{56}$, las máquinas confiscadas (entre la que se encontraba la de El Tradicionista) se adjudicarían a los diferentes estados, con el fin de dotarlos de las máquinas y utensilios necesarios para el funcionamiento de la imprenta y para estimular la publicación de periódicos que impulsaran los intereses del gobierno e incentivaran el conocimiento entre estados $^{57}$. Atendiendo a que Rojas entró en la escena editorial de Neiva en 1879 con la publicación de La Unión Liberal, y que luego de ese año proliferaron los periódicos en Neiva, es plausible que una de las imprentas confiscadas en Bogotá desde 1876, como la de La Ley y El Tradicionista, pudiera llegar a la ciudad y convertirse el motor de la Imprenta de Neiva, es decir, la imprenta oficial del Estado.

54 «Expropiación de la imprenta de 'El Tradicionalista'. Memorial», en Valderrama, El centenario de El Tradicionista, 72-74.

55 «Expropiación de la imprenta de 'El Tradicionalista'. Memorial», en Valderrama, El centenario de El Tradicionista, 76-77.

56 Diario de Cundinamarca, Bogotá, 2 de junio de 1877.

57 Diario de Cundinamarca, Bogotá, 2 de junio de 1877. 
El diseño de La Estrella fue constante durante su existencia en tamaño, diseño y extensión. Un cambio notorio ocurrió en su cabezote, escueto hasta el número 91:

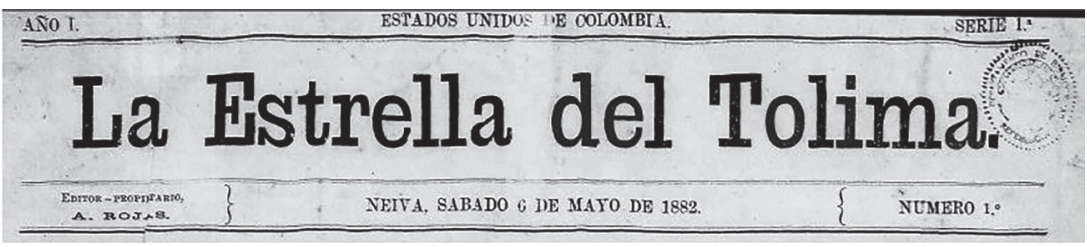

Imagen 1. Cabezote de La Estrella del Tolima hasta el número 91.

Fuente: La Estrella del Tolima, número 1 (6 de mayo de 1882), Neiva.

Y expresivo y bellamente evocador desde el número 92:

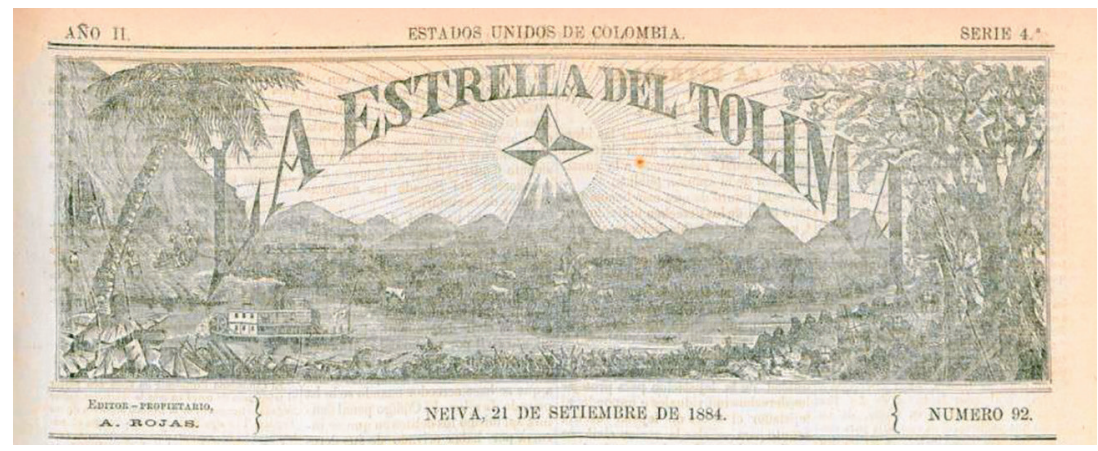

Imagen 2. Cabezote de La Estrella del Tolima desde el número 92.

Fuente: La Estrella del Tolima, número 92 (21 de septiembre de 1884), Neiva.

El cambio en el cabezote permite comprender dos cosas: por un lado, el nombre del periódico, y por otro, las bondades de la región que se querían rescatar. Según los editores, el cabezote sugería que:

El liberalismo ha calado en este Estado con raíces profundas i vive en los espíritus con la magnifica vida de una naturaleza tropical. Bajo este sol, en estas vegas, ante este rio es imposible no amar la libertad, que es luz como el sol, que se fecunda como esas vegas i lleva como ese rio la fuerza impulsiva, encerrando en cada olaje un jermen de vida i progreso. Esa estrella que ilumina por encima de las altas nieves, eternas como el derecho, es estrella de libertad que quiere dar luz y vida a la democracia ${ }^{58}$.

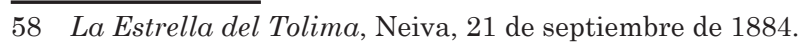


Entre el contenido de La Estrella aparece un extenso y conspicuo homenaje a los fallecidos en tiempos de la publicación, a saber: Liborio Durán, Manuel Ancízar, María Concepción Tello de Arciniegas, Francisco Javier Zaldúa, Miguel María Durán (redactor de La Estrella) y José María Rojas Garrido. Rendir homenaje a los liberales fallecidos fue una manera de rendir tributo a sus partidarios $\mathrm{y}$, sobre todo, un mecanismo de los redactores para llamar a la cohesión del partido a través de figuras como Durán y Rojas Garrido, quienes desde su perspectiva representaban el arquetípico del ser liberal. En otras palabras, personajes empleados como figuras retóricas para combatir la desintegración del liberalismo.

\title{
La Estrella del Tolima, último aliento del liberalismo radical del Tolima
}

El 6 de mayo de 1882 circuló en Neiva el primer número de $L a$ Estrella y anunciaba:

\begin{abstract}
Esta hoja no tiene programa. Fundada para sostener los intereses de la causa liberal en la República, tomará el rumbo que los principios de esta escuela determinen en el curso normal o imprevisto de los acontecimientos políticos. Destinada igualmente a servir a los intereses especiales del Tolima, sus columnas serán ocupadas preferentemente con todo lo que tenga relación con la marcha administrativa, intelectual i comercial del Estado (...) LA EsTrELLA DEL Tolima, fundada con elementos propios, i sostenida, como lo esperamos, por el concurso patriótico del liberalismo tolimense, llevará una existencia independiente de los poderes públicos i procurará ser, hasta donde sea posible, el eco de los intereses sociales i la voz moderada pero enérjica de la opinión sensata del Estado ${ }^{59}$.
\end{abstract}

La causa "liberal de la República" que defendía $L a$ Estrella era el liberalismo radical. Al asumirse como el verdadero liberalismo, los radicales que hacían parte y tenían negocios con el gobierno del Estado emplearon el periódico como vehículo para dar a conocer su interpretación sobre la situación del país y del Tolima. Su objetivo, era lograr el

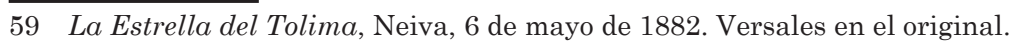


fortalecimiento del partido que, como hemos dicho, había perdido el poder frente a los liberales independientes. Para desentrañar la naturaleza de este último aliento del liberalismo radical tolimense estudiaremos La Estrella desde lo político, a través de dos ejes: primero, la situación federal y la estrategia asumida por los redactores del periódico cuando el radicalismo era una minoría en el gobierno central; y segundo, la lectura de la situación del Tolima, prestando atención a la estrategia para mantener a los radicales en el gobierno del Estado.

\section{La Estrella del Tolima y la situación nacional}

Bajo el subtítulo "Lo que hubo i lo que hai", en su primer número los redactores presentaron un balance sobre la situación del país desde 1876, en él, afirmaban que el 1 de abril de 1878, inicio de la presidencia Julián Trujillo, era una fecha nefasta para la República, en contraste con la "gloriosa", para ellos, presidencia de Aquileo Parra.

En el editorial se interpretó al discurso de clausura presidencial de Parra como un llamado a la unión de los liberales, pues se dirigía a "la gran masa liberal de la República, con el abrazo fraternal de la más sincera reconciliación" ${ }^{60}$. Además, se definía a Parra como un modelo de: presidente, ciudadano y soldado, hasta el punto de ser considerado el verdadero vencedor de la guerra de 1876, el Carnot colombiano ${ }^{61}$. En contraste, Trujillo es descrito como un caudillo que, motivado por una ofuscación incomprensible, se convirtió en "instrumento inconsciente de las ambiciones personales de unos pocos" ${ }^{62}$ y dio en la cara "con el puño de su espada, a la parte más distinguida de sus compañeros del día anterior". Los radicales en La Estrella acusaban a Trujillo de traidor, de dejar al Partido Liberal "próximo a su caída,

60 La Estrella del Tolima, Neiva, 6 de mayo de 1882.

61 Se refieren a Lazare Nicholas Marguerite Carnot, quien durante la Revolución Francesa fue miembro más activo del comité de seguridad pública, cuyas innovaciones en entrenamiento, equipo y estrategia, fueron un factor determinante en la victoria de los ejércitos franceses en 1793. Sobre Carnot ver David Eugene Smith, «Lazare Nicholas Marguerite Carnot», The Scientific Monthly 37, nº 2 (1933): 188-189.

62 La Estrella del Tolima, Neiva, 6 de mayo de 1882. 
vendida su existencia como se vendió la de Cristo, por los treinta denarios de un miserable sueldo"63.

Los redactores de La Estrella establecieron otra fecha como clave, el 1 de abril de 1882, día de posesión Francisco Javier Zaldúa en la presidencia de los Estados Unidos de Colombia. Para ellos, este suceso representó un "cambio de frente" y "la esperanza de mejores días para la causa liberal". Según ellos, con Zaldúa se había quitado la bandera de la discordia que Trujillo dejó en el palacio nacional, y quedó en su lugar "a todo viento, el jeneroso estandarte de la reconciliación liberal, firmemente empuñado por la nerviosa mano de un anciano que al despedirse de la vida, legará a la juventud i a la historia, el precioso tesoro de tan patriótico ejemplo"64.

Apoyar la candidatura de Francisco Javier Zaldúa, liberal independiente, fue la estrategia que propusieron los radicales Aquileo Parra, Santos Acosta, Santiago Pérez y Eustorgio Salgar en el marco de la unión liberal organizada el 24 de abril de 1881. Mediante el respaldo a Zaldúa buscaban reabsorber a los dirigentes independientes ${ }^{65}$, y efectivamente lo consiguieron, gracias al apoyo de figuras como: Julián Trujillo, Pablo Arosemena, Salvador Camacho Roldán y Hermógenes Wilson ${ }^{66}$, los cuales se unieron al directorio radical con intenciones de debilitar a Núñez.

El apoyo radical a Zaldúa fue recompensado con el nombramiento de algunos radicales en las secretarías del país, a saber: Felipe Zapata (Relaciones Exteriores), Wenceslao Ibáñez (Guerra y Marina) y José María Villamizar (Tesoro). Los nombramientos no fueron bien recibidos por Núñez y los independientes, quienes hicieron oposición en el Congreso rechazándolos y obligando al presidente, según las leyes vigentes, a proponer a otras personas para los cargos. En este contexto, los redactores de La Estrella iniciaron con

63 La Estrella del Tolima, Neiva, 6 de mayo de 1882.

64 La Estrella del Tolima, Neiva, 6 de mayo de 1882.

65 Park, Rafael Núñez and the Politics, 306.

66 Park, Rafael Núñez and the Politics, 311. 
la defensa de Zaldúa y la dignidad de los líderes radicales y su derecho a participar activamente en política, violentado, en ese entonces, por la exclusión de los independientes que dirigían desde el Congreso.

Esta defensa encontró una respuesta antagónica desde La República. En esta publicación, liberal independiente, defendían la candidatura a la presidencia de Núñez (18801882) y se le definía como un camino al porvenir ${ }^{67}$, mientras se identificaba a los radicales como la causa de la división liberal:

Los radicales no tienen confianza en el señor Zaldúa, y esto porque aunque él quiso darles participación en el Gobierno, no ha cedido a dejarse arrastrar por la política del odio y de la persecución en nombre de la tolerancia y la concordia. Ellos aparentan ser directores de la nueva política, pero allá, en el seno de la intimidad, comprenden que nada de lo que sueñan por ahora podrá realizarse. Todo su trabajo es preparar el terreno para la futura Presidencia ${ }^{68}$.

El discurso de los independientes se presenta como contrario al de La Estrella y sus redactores. Para los radicales el peligro no estaba en los conservadores, sino en los independientes, quienes estaban fortalecidos y les habían despojado del poder en el país. Por tanto, la polémica por Zaldúa en La Estrella es en el fondo la pelea contra Núñez y el liberalismo independiente, contra la división que los radicales asemejaban a una traición, como se extrae del siguiente editorial:

Presentimos que se fragua alguna conspiración contra el órden, i, vemos que esta conspiración se desarrolla en forma de una larga provocación a los pueblos, que partiendo de unos poquísimos descontentos, va a reflejarse en el seno mismo del Senado, en donde encuentra voces harto antipatrióticas que la repercutan, le presten aliento i le hagan difundir en las masas. ¿De quien parte esta larga provocación al asalto del órden público i en qué forma se ejercita esa provocación?

67 La República, Neiva, 3 de abril de 1882.

68 La República, Neiva, 19 de junio de 1882. 
Vamos a decirlo. Esa provocación parte del espiritú transtornado de algunas ambiciones personales burladas, i de algunas conciencias endurecidas i enfermas ${ }^{69}$.

Cuando los redactores de La Estrella mencionaban las ambiciones personales se referían a Núñez y los independientes, a quienes controvertían constantemente por las publicaciones del periódico $L a L u z$ de Bogotá, en el que Núñez era colaborador. Como muestra de ello traemos a colación un editorial de La Estrella en el que los liberales radicales del Tolima respondieron al artículo publicado en el número 131 de La Luz bajo el nombre de "Filosofía de la situación”:

El hábil estadista, que, no contento con los males causados por sus desaciertos, debilidades i corruptelas, se obstina aun en restablecer el dominio de los abusos y en oponerse a las justas reparaciones que la moral i el derecho nacionales reclaman después de tanto escándalo, de tanto atropello i de tanto desvergonzado ultraje al buen sentido de los colombianos. Si no estuviéramos en posesión de la seguridad de que la intelijencia del principal Redactor de La Luz es una de las mas privilejiadas del país, i de que ha dado pruebas de una vasta ilustración: al leer el artículo de que nos ocupamos, podríamos, sin temor de que se nos apellidara temerarios, calificar de estúpida la mano que trazó aquellas líneas o de demente la cabeza que abrigó tales conceptos ${ }^{70}$.

Mediante textos como el anterior, en La Estrella se difundía la imagen de Núñez como un estadista corrupto y obstinado, el artífice y representación de la división del liberalismo. Esta imagen se opone a publicaciones independientes como $L a L u z$, en la cual Núñez es figura de reconocimiento y homenaje porque, según los redactores y colaboradores, encaminó al país por el sendero de la regeneración administrativa. Tratamiento semejante se hace del problema de las relaciones entre el Congreso y Javier Zaldúa, pues mientras en $L a L u z$ se insistió en que el Congreso no hacía más que defender las políticas de la presidencia de

69 La Estrella del Tolima, Neiva, 10 de junio de 1882.

70 La Estrella del Tolima, Neiva, 24 de junio de 1882. 
Núñez, en La Estrella se presentó a Zaldúa como el hombre de la unidad liberal atrapado por la conspiración de corruptos como Núñez. No podía ser de otro modo, pues $L a L u z$ era palestra de los liberales independientes nuñistas y del mismo Núñez, mientras que La Estrella era el baluarte del radicalismo en el Tolima ${ }^{71}$.

Bajo el título "Nuestro Programa", los redactores de $L a$ Estrella afirmaron que sus ataques a Núñez y el personalismo habían sido realizados "con moderación, pero con energía republicana"72, y que respondían a la necesidad de fortalecer las doctrinas liberales y el espíritu de conciliación, debilitados por "las fatídicas sombras" que se habían interpuesto en el camino de la conciliación turbando las esperanzas de paz. Claramente se referían a los liberales independientes, nombrándolos Iscariotes, es decir, traidores. No obstante, en el citado editorial también se indica que cambiaría el tono de su discurso en caso de un acuerdo en Bogotá entre el presidente y los congresistas, pues en ese caso estarían dispuestos a deponer sus denuncias. Así pues, en La Estrella se declaraba abierta al diálogo siempre que en Bogotá se acabara la oposición del Congreso a Zaldúa.

La invitación al diálogo y aparente justificación del lenguaje con el que se habían referido a los independientes respondía a los acercamientos entre las fuerzas políticas en Bogotá. Estos acercamientos se interpretaron en la sección "Interior", bajo el título "Correspondencia especial de La Estrella", como evidencia de la "decadencia del nuñismo" Este optimismo, que también se manifestaba en los números 13 y 14 del periódico, decayó cuando el Congreso rechazó los nombramientos de Eugenio Castilla ${ }^{74}$ y Felipe Pérez en sus puestos como secretarios.

71 La Estrella del Tolima discute sobre el contenido de La Luz en los números: 1, $3,6,8,9,11,12,15,27,28,29,33,34$, entre otros. En ellos crítica el personalismo de Núñez.

72 La Estrella del Tolima, Neiva, 22 de julio de 1882.

73 La Estrella del Tolima, Neiva, 22 de julio de 1882.

74 Fue presidente del Estado Soberano del Tolima en 1863 y presidente provisorio del Tolima en 1867. José María Restrepo Sáenz, Gobernadores y Próceres de Neiva, 
El rechazo del Congreso al nombramiento del tolimense Eusebio Castilla realizado por Zaldúa, fue entendido desde La Estrella como una deslealtad, una muestra de la desmoralización de la conducta política y un desmán para con el Estado Soberano del Tolima ${ }^{75}$. Ante lo sucedido, los redactores de La Estrella se preguntaron por los caminos que le quedaban al liberalismo, los cuales se resumían a dos: rebelión o acatamiento. "El pueblo" (entiéndase los liberales) se encontraba, según los redactores:

[...] entre el derecho i la violencia, entre la libertad i la esclavitud, entre la autonomía i el vasallaje, i entre la cadena i la lei, [pues] el pueblo, que en el réjimen legal es soberano, i en la dictadura la víctima, es quien debe escoger. Los dos términos del dilema son tan terribles, que la mano tiembla al optar por cualquiera de ellos ${ }^{76}$.

Una vez la guerra volvió a hacer parte del lenguaje de la publicación, Núñez, más que antes, fue objeto de críticas. El ambiente de guerra se hizo también visible en artículos como "La hora suprema se aproxima" 77 , en el que los redactores analizaron la situación del liberalismo en los estados y concluyeron que el nuñismo, si bien tenía el control de las asambleas de Panamá, Boyacá, Bolívar, y Cundinamarca, estaba dividido y era vulnerable, por tanto, estaba cerca "la hora suprema", cuando los radicales llenarían el vacío y subsanarían la división liberal.

Como observamos, los radicales de La Estrella defendían a Francisco Javier Zaldúa aun cuando no fuera un radical, pues asumieron que negociar era su mejor estrategia ante la imposibilidad de lanzar a su propio candidato y ganar. Luego del fallecimiento de Zaldúa el 21 de diciembre de 1882, su remplazo a cargo del gobierno fue José Eusebio Otálora ${ }^{78}$,

\footnotetext{
(Bogotá: Editorial ABC, 1951), 356-358

75 La Estrella del Tolima, Neiva, 12 de agosto de 1882.

76 La Estrella del Tolima, Neiva, 19 de agosto de 1882.

77 La Estrella del Tolima, Neiva, 26 de noviembre de 1882.

78 El primer designado era Rafael Núñez, por tanto tenía la primera opción para reemplazar a Zaldúa. Sin embargo, esperando que Otálora le fuera leal al liberalismo
} 
el mismo que figuró en el cambio de gobierno de radical a independiente en Boyacá.

En un primer momento los redactores de La Estrella centraron su atención, aunque con prevención, en la figura de Otálora debido a su filiación independiente ${ }^{79}$. Sin embargo, el 29 de julio de 1883, siguiendo las instrucciones recibidas desde Bogotá, anunciaron su candidatura presidencial para el período $1884-1886^{80}$. No obstante, la estrategia de los radicales fue un fracaso, pues, como se observa en La Estrella a pesar de que los radicales afirmaban que Otálora fortalecería la unión liberal, la concordia y la paz con la que podrían regresar al poder, este fue indeciso y rechazó su postulación presidencial ante las presiones nuñistas ${ }^{81}$.

Otálora renunció a la presidencia en un ambiente adverso en el Congreso y fue reemplazado el 1 de abril de 1884 por Ezequiel Hurtado en calidad de designado. El 1 de agosto de 1884 luego de unas elecciones en las que los radicales apoyaron a Solón Wilches y solo obtuvieron los votos de Antioquia, Santander y Tolima, Rafael Núñez obtuvo por segunda vez el cargo de presidente de los Estados Unidos de Colombia, lo que hizo evidente que las reformas adversas al radicalismo continuarían, al igual que el proceso de centralización del poder político. En esas condiciones, los redactores de La Estrella se encontraban en un escenario adverso, donde el artífice de la división del liberalismo se encontraba de nuevo a cargo del gobierno nacional, ratificando la debilidad del radicalismo. Los redactores del periódico, propusieron defender al primer magistrado de la Unión mientras persistiera "en las sanas intenciones que lo animan" 82 ; caso contrario, "si los elementos nocivos que dominan entre los reaccionarios se impusieren a

independiente, rechazó la posibilidad para no inhabilitarse para en su aspiración presidencial para el siguiente periodo que comenzaba en 1884 .

79 La Estrella del Tolima, Neiva, 7 de enero de 1883.

80 La Estrella del Tolima, Neiva, 29 de julio de 1883.

81 Mejía Arango, Los Radicales, 582.

82 La Estrella del Tolima, Neiva, 10 de septiembre de 1884. 
su política" ${ }^{33}$, la respuesta debía ser combatirlos "por la Patria, por la libertad".

La Estrella dirigió su atención al Estado Soberano de Santander debido a los levantamientos en armas contra el general Solón Wilches, el cual era acusado de fraude electoral ${ }^{84}$. La amenaza de guerra hizo parte del contenido en el periódico, donde los acontecimientos de Santander eran tratados como si fueran propios del Tolima. La disolución de la convención en Santander fue interpretada como una afrenta al liberalismo radical por parte del gobierno de Núñez, y sus redactores acusaron al presidente federal de llevar el país a la guerra:

La situación del pais impone una política que no es esa que disuelve los senados populares e impone la arbitrariedad como lei [...] levantamos la voz para decir al señor Núñez que ha perdido el camino de la política que pronosticaba cuando se declaró irrevocablemente liberal. Estamos viendo los dos caminos i los dos horizontes hácia los cuales se dirijen: en el mapa de la política se señalan con toda claridad esas opuestas vías i no comprendemos cómo se deja éste que se lleva por la paz a la reorganización, para tomar aquella que conduce por la guerra a la descomposición ${ }^{85}$.

Los radicales del Tolima temían que la situación en Santander desencadenara una guerra general para la que no estaban preparados. La estrategia de plegarse ante el gobierno central esperando desarrollar alianzas que les dieran participación, resultó un fracaso frente a la preponderancia que les arrebataron los independientes. Mientras la situación del país era adversa a los radicales, en el Tolima también existía la división liberal. Frente a dicha situación La Estrella tenía un rol que desempeñar, debía fortalecer el liberalismo radical en el Estado.

83 La Estrella del Tolima, Neiva, 10 de septiembre de 1884.

84 Mejía Arango, Los Radicales, 596-597.

85 La Estrella del Tolima, Neiva, 7 de diciembre de 1884. 


\section{La Estrella del Tolima, publicación semioficial del gobierno del Tolima}

Los liberales radicales eran el sector político preponderante en el Tolima cuando inició la publicación de La Estrella el 6 de mayo de 1882. En 22 de julio de 1882 (núm. 12), sus redactores presentaron un balance sobre lo que fueron sus primeras 11 entregas, en él afirmaban haber defendido la causa liberal, pues habían informado, según ellos, sobre lo que había pasado y estaba pasando en las "misteriosas rejiones en donde se ventilan las cuestiones trascendentales de la alta política en el país"s6.

En su editorial los redactores informaron que los asuntos del Tolima estaban en un segundo plano, supeditados a la atención que prestaban a la política federal. La ausencia en La Estrella de asuntos como los debates electorales en el Tolima, se debe a que al parecer daban por sentado que las fuerzas del radicalismo en el Estado eran lo suficientemente fuertes para mantener el control sobre los cargos del gobierno. Lo que les interesaba era la presidencia de los Estados Unidos de Colombia, ya que era allí donde preveían las consecuencias nefastas de la división liberal.

Contrario a los deseos de los redactores, en 1882 la elección de presidente del Estado Soberano del Tolima del año siguiente suscitó interés en los suscriptores, quienes se manifestaron mediante correspondencia remitida al periódico ${ }^{87}$. La sección editorial se ocupó de estas cartas, no para promover a un candidato en particular, sino para hacer un llamado a la unión y el acuerdo entre los liberales en los siguientes términos:

Nuestra hoja, de ninguna manera, i bajo pretesto alguno, terciará en el debate electoral, si por desgracia el partido liberal no obra unido, sus esfuerzos se encaminarán a

86 La Estrella del Tolima, Neiva, 22 de julio de 1882.

87 Algunos estudios sobre el Estado Soberano del Tolima son: Delimiro Moreno, El Huila en el Siglo XIX, (Bogotá: Vargas editor, 1994) y Álvaro Cuartas Coymat, Tolima Insurgente, (Bogotá: Pijao Editores, 1991). 
mantener la uniformidad de los intereses de nuestra común agrupación, a defender la bandera, a servir a nuestra causa, a evitar a la Patria nuevos dolores, i a salvar de toda querella a este caro suelo, ya acostumbrado al sosiego, impaciente por el trabajo e imperturbable i sereno en la vida normal de la constitucionalidad. Pero si notamos que la renovación del poder va a verificarse mediante una lucha ardiente contra nuestros adversarios políticos, para quienes pedimos amplia garantía, nosotros cumpliremos nuestro deber, porque en el terreno de la doctrina no sacrificamos ni un ápice de nuestras ideas, i en el terreno de la práctica sabemos que el cambio de partidos en el poder público, es jenerador de un cambio de instituciones ${ }^{88}$.

Mientras se desarrollaba el debate electoral del que $L a$ Estrella se marginaba con su propio silencio, en la sección de colaboradores se publicó un texto de A. Terreros, con el título "Los tres circuitos electorales en el Tolima" ${ }^{\text {. Terreros }}$ lamentaba la inferioridad del departamento del Norte en la Asamblea Departamental, pues mientras los departamentos del Centro y Sur contaban con 13 diputados cada uno, el Norte solo tenía 9, medida que dice fue tomada por los radicales a raíz de la guerra de 1876-1877. Terreros no estaba equivocado, pues los radicales victoriosos en la guerra, decidieron en la Asamblea Constituyente limitar el poder del norte del Estado, zona controlada por los conservadores que dirigieron el destino del Tolima entre 1867 y 1876 . El establecimiento de la capital en Neiva respondió al mismo interés de debilitar al norte y fortalecer al sur.

Los redactores de La Estrella publicaron la contribución de Terreros para comentarla en su siguiente número ${ }^{90}$. En su respuesta, proponían realizar un censo para obtener información que permitiera distribuir de manera equitativa el número de delegados por circuito. El análisis sobre un tema del Estado en la sección editorial no era común en $L a$ Estrella, consideramos que era tan evidente el descontento en el departamento del Norte, y tan difícil de justificar, que los

88 La Estrella del Tolima, Neiva, 31 de diciembre de 1882.

89 La Estrella del Tolima, Neiva, 24 de diciembre de 1882.

90 La Estrella del Tolima, Neiva, 11 de febrero de 1883. 
radicales del Tolima ofrecieron soluciones al público, aunque no tenemos evidencia de que se haya realizado dicho censo.

A pesar de los comentarios sobre los circuitos electorales, los redactores se negaron a apoyar a un candidato para las elecciones que se realizarían. La Estrella dejó ese debate local en manos de otros periódicos. Los candidatos liberales eran: Acisclo Molano, Clímaco Iriarte ${ }^{91}$ y Gabriel González Gaitán ${ }^{92}$. El primero abiertamente liberal independiente, el segundo radical apoyado por algunos independientes y conservadores, y el último radical ${ }^{93}$; por los conservadores competía Pastor Herrera. La ausencia de La Estrella en el debate le ocasionó reclamos, según la misma publicación. Explicaron nuevamente que su intención no era contribuir a la división liberal, pues los candidatos con opciones eran todos de ese partido ${ }^{94}$. Al final, aceptaron publicar las adhesiones a los candidatos liberales remitidas a su redacción empezando con González Gaitán. Cuando expresaron no conocer otras adhesiones ${ }^{95}$, partidarios de otros candidatos protestaron y los editores decidieron darle cabida a "todo lo que se publique en materia de candidaturas" incluidas hojas volantes.

Según un corresponsal de Honda ${ }^{97}$, la publicación de adhesiones a Iriarte se hizo demasiado tarde. El corresponsal felicitaba a La Estrella por buscar la unión del Partido Liberal, pero agregaba que el silencio durante el debate electoral, el haberse quedado "cruzados de brazos", empeoraba la división,

91 Los partidarios de Clímaco Iriarte hicieron uso de El Bien Público. Órgano de los intereses del partido Liberal del Tolima, dirigido por Eusebio Castilla, publicación en la que planteaban la necesidad de unir al Partido Liberal alrededor de una figura con la importancia de Iriarte.

92 Gabriel González Gaitán fue en 1853 gobernador de la provincia de Neiva y representante al Congreso; en 1879 secretario de Gobierno del Tolima de Ignacio Manrique Calderón y luego de Marcelo Barrios, a quien aspiraba suceder. Sus partidarios defendieron su candidatura en El Elector. Órgano del partido liberal unionista del Tolima.

93 Moreno, El Huila en el siglo XIX, 168.

94 La Estrella del Tolima, Neiva, 8 de abril de 1883; 15 de abril de 1883.

95 La Estrella del Tolima, Neiva, 29 de abril de 1883.

96 La Estrella del Tolima, Neiva, 6 de mayo de 1883.

97 «Gacetilla», La Estrella del Tolima, Neiva, 6 de mayo de 1883. 
pues había dejado a los liberales "embrollados". El corresponsal afirmaba no saber cuál era el mejor candidato, pero sí saber que el Estado necesitaba un presidente que cerrara las puertas al nuñismo, rechazara las invasiones contra el Estado y tuviera "los merecimientos de Fruto Santos para el Partido Liberal doctrinario y la honradez y criterio de Marcelo Barrios" ${ }^{98}$. El tratamiento que recibió Clímaco Iriarte nos presenta una división no tan clara con los independientes en el Tolima, en la que corresponsales como el de Honda categorizaban como radical a un candidato apoyado por independientes.

Esta actitud pasiva frente a la contienda ocasionó que los redactores de La Estrella fueran criticados por El Diario de Cundinamarca, publicación considerada por ellos mismos como "el decano de la prensa liberal en Colombia"99. El diario los recriminaba por no dar a conocer ni apoyar a su candidato para las elecciones de presidente del Tolima ${ }^{100} \mathrm{y}$, en último término, por no cumplir sus deberes como órgano radical que debía informar y orientar a los liberales tolimenses. La Estrella se defendió argumentando que quería evitar la división del liberalismo, de la cual los Estados Unidos de Colombia era víctima. La contienda continúo, luego que el Diario de Cundinamarca acusara a La Estrella de favorecer a Gabriel González, a quien consideraba un candidato de imposición oficial desde el gobierno del Tolima en el que era secretario de Gobierno.

La Estrella defendió la imagen de González diciendo que era un candidato idóneo y que no necesitaba su apoyo, pues el pueblo tolimense lo conocía y elegiría a quien mejor le pareciera $^{101}$. Se nos presenta entonces un candidato que hacía parte del gobierno radical del Tolima, en el cual Miguel María Durán ocupaba el cargo de secretario de gobierno del Tolima y Alejandro Rojas el de presidente de la Corporación Municipal de Neiva. Entonces no es extraña la acusación.

98 La Estrella del Tolima, Neiva, 6 de mayo de 1883.

99 La Estrella del Tolima, Neiva, 20 de mayo de 1883

100 La Estrella del Tolima, Neiva, 27 de mayo de 1883.

101 La Estrella del Tolima, Neiva, 3 de junio de 1883. 
En los números que siguieron, La Estrella siguió centrando su atención en el desarrollo de la campaña para presidente del Estado, que según sus editoriales, profundizaba la división liberal, pues se enfrentaban tres candidatos del mismo partido, mientras que los conservadores habían sabido escoger a uno y apoyarlo. En esta coyuntura, circuló en mayo una hoja volante de la imprenta de A.P. en la ciudad de Neiva, bajo el nombre de Defensa de un ciudadano ${ }^{102}$, en la cual Eusebio Castilla, firmando como presidente del Comité Liberal Central del departamento del Sur, se dirigía a los lectores de La Estrella para manifestar que se preocupaba por la división en las filas el partido radical y el haber sido atacado en $L a$ Estrella $^{103}$, con motivo de la circular que como presidente del Comité Central Liberal del departamento del Sur del Estado del Tolima dirigió a José Benito Gaitán, impresor del Diario de Cundinamarca.

La raíz de la disputa se encuentra en la elección del Comité Central del departamento del Sur. Según los editores de La Estrella la convocatoria fue pública y abierta a todos los liberales y se realizó el 21 de abril en el Colegio Santa Librada. Entre sus integrantes se nombraron a: José María Lombana, Ignacio Antonio Trujillo y Miguel María Durán, entre otros. En opinión de Castilla esa fue una reunión de empleados del gobierno del Estado Soberano a la que no fueron invitados los liberales importantes de la capital (Neiva), por lo que era una maniobra política.

Eusebio Castilla afirmaba que los liberales que no eran del gobierno, se reunieron el día siguiente y lo eligieron en el comité junto a Liborio Díaz, Ramón Salas y Eugenio Castilla ${ }^{104}$. A su vez, los redactores de La Estrella publicaron cartas de ciudadanos que concurrieron a la reunión del 21 como prueba para acusar a Castilla de mentir, pues los testigos decían desconocer que se hubiera realizado una reunión como la que menciona Castilla, negando incluso que hubiera un lugar

102 Defensa de un Ciudadano, (Neiva: Imprenta de A.P. 1883).

103 Se refiere al número 55 de La Estrella publicado el 20 de mayo de 1883.

104 La Estrella del Tolima, Neiva, 20 de mayo de 1883. 
diferente al Santa Librada que tuviera la capacidad para realizar tal reunión ${ }^{105}$. Castilla se defendió en la polémica con la transcripción de una carta en la que dirigentes liberales del Tolima ${ }^{106}$ le informaban que se comprobó fraude en la convocatoria a la Junta del 21. Según Castilla, los dirigentes del partido le recomendaron guardar silencio para evitar confrontaciones entre liberales en tiempos de elecciones.

Las elecciones tolimenses del 2 de septiembre de 1883 dieron el triunfo a Gabriel González Gaitán ${ }^{107}$ frente a Acisclo Molano, pues Clímaco Iriarte había renunciado en agosto ${ }^{108}$. Gaitán se posesionó de la presidencia del Estado Soberano el 15 de diciembre y se refirió al estado político en los siguientes términos:

La agitación que hace pocos meses llevó á los ánimos la alarma y la inquietud y que hizo creer en un próximo trastorno del orden público, tanto de la Nación como del Estado, ha venido lentamente entrando en reposo, en términos que hay quienes crean que la situación política está perfectamente despejada. Sin embargo, permanecen pequeñas sombras sobre el horizonte político que no dejan ver claro el porvenir de la República, esto hace pues creer que es necesario poner alguna atención á ese asunto ${ }^{109}$.

La agitación a la que se refiere el presidente del Estado en su alocución no es ninguna en particular, pues en La Estrella, casi que de manera constante se planteaba la inminencia de una guerra en la que los radicales tendrían que participar para defenderse. No hablaban de lanzarse a la guerra a retomar lo que fue suyo, mas bien era para garantizar su supervivencia.

105 La Estrella del Tolima, Neiva, 20 de mayo de 1883.

106 Valentín Trujillo, Benito Salas, Timoleón Cabrera, Ramón Manrique, Uldarico Scarpetta, José Núñez, Heraclio Padilla, José M. Cuéllar, Emilio Cabrera y Josué Tello.

107 La Estrella del Tolima, Neiva, 9 de septiembre de 1883.

108 El Bien público, Neiva, 18 de agosto de 1883.

109 A los Habitantes del Estado, (Neiva: Imprenta del Estado, 15 de diciembre de 1883). s.p. 
La polémica por las elecciones de presidente del Tolima continuó aun después de que finalizaron. Liberales independientes publicaron en junio 1883 una hoja volante titulada La cuestión Tolima, la actitud del Centro, en la que defendían la necesidad de que el liberalismo se uniera a los conservadores alrededor de Acisclo Molano. En La Estrella, luego de conocerse la victoria de González Gaitán, se publicó una inserción con el título "Contestación necesaria" autor con el seudónimo "un viejo liberal" afirmó escribir desde Purificación el 1 de julio de 1883. La inserción controvirtió el argumento principal de La cuestión Tolima, que era la historia de las alianzas entre liberales mosqueristas y conservadores, calificándola como la unión nefasta, pues con ella los liberales perdieron entre 1867 y 1876 la preponderancia en el gobierno del Estado.

Los independientes a su vez respondieron a La Estrella mediante una hoja volante llamada Un viejo liberal, de autoría de José María Pérez ${ }^{111}$, quien argumentaba que los hechos no fueron como se presentaban en La Estrella, pues los liberales independientes, según él, no eran mercenarios ni traidores, sino que al contrario, mantenían los principios radicales. Usaba como ejemplo las administraciones de Zaldúa y Otálora, que fueron apoyadas por los radicales y mantuvieron, según José María Pérez: "el respeto a la soberanía de los Estados, la tolerancia política y religiosa, la inviolabilidad del sufragio, la paz, el orden y el respeto a las mayorías"112. Los independientes en el Tolima se cobijaban en el discurso con los principios radicales como parte de su estrategia para alcanzar el poder en un Estado con gobierno radical; se presentaban como parte integrante de la unión liberal, mas no como causantes de la división que atacaban los editores de La Estrella.

110 La Estrella del Tolima, Neiva, 9 de septiembre de 1883.

111 Un viejo liberal, (Neiva: Imprenta de A.P. 16 de octubre de 1883.) José María Pérez fue candidato de los liberales independientes para la presidencia del Estado Soberano del Tolima en el periodo 1882-1883. Fue derrotado por el radical Marcelo Barrios.

112 Un viejo liberal. 
Precisamente, el tema de la unión liberal fue central en el Estado Soberano del Tolima y se exacerbó durante las elecciones de 1883, en las que radicales e independientes querían la unión liberal, pero bajo su mando. El radical José María Álvarez publicó en la imprenta de Alejandro Rojas una hoja volante con el nombre de La Unión Liberal en el Tolima y su programa ${ }^{113}$; para discutir el programa político de unión presentado por Clímaco Iriarte y Napoleón Borrero el 23 de septiembre de 1883. En la hoja se argumentaba que los independientes carecían de doctrina, que eran responsables de la división liberal, y que la propuesta de Iriarte y Borrero no correspondía con la propuesta de los radicales.

En respuesta la hoja de Álvarez, Napoleón Borrero defendió a los independientes y la propuesta de unidad liberal de Clímaco Iriarte en su texto Rectificaciones a la hoja titulada La Unión Liberal en el Tolima y su programa ${ }^{114}$, publicado en la imprenta $L a L u z$ de la ciudad de Bogotá. El principal argumento de Borrero era que los radicales eran loscausantes de la división del liberalismo. Los independientes argumentaron que una vez los radicales ganaron en las elecciones de 1883 en el Tolima, para la Asamblea y la presidencia del Estado, se habían dedicado a calumniar y excluir a los independientes, aprovechando para ello a La Estrella, publicación que tildan de semioficial ${ }^{115}$ y de ser un instrumento del presidente del Tolima semejante a la Gaceta del Tolima. La denuncia de los independientes sobre la cercanía entre La Estrella y el gobierno radical del Tolima retomaba la que en su momento hicieron los editores del Diario de Cundinamarca.

Los redactores de La Estrella precisaron su idea sobre la unión liberal ${ }^{116}$. En su interpretación, "el liberalismo, dividido

113 La Unión Liberal en el Tolima y su programa, Neiva, Imprenta de A. Rojas. 10 de enero de 1884.

114 Rectificaciones a la hoja titulada La Unión Liberal en el Tolima y su programa, (Bogotá: La Luz, 1884).

115 Rectificaciones a la hoja titulada La Unión Liberal en el Tolima, 7.

116 La Estrella del Tolima, Neiva, 5 de agosto de 1884. 
en la Nación, se dividió también en el Tolima"117, lo que consideraban como natural dada la existencia de radicales e independientes. La división del radicalismo de 1883 en el Tolima la definieron como incidental, como superada. Destacaban que la importancia del Tolima para el liberalismo en el país, consistía en la posibilidad de que ese Estado fuera "el vocero e iniciador de un programa del liberalismo puro [...] el primero en iniciar la gran transformación del porvenir", el que diera ejemplo como partido que solo tenía "que luchar contra los enemigos de sus ideas", contra los que ocho años antes (1876) "burlaban los derechos del pueblo tolimense i los dominaban con férrea mano".

La unión liberal que propuso La Estrella no pudo ser alcanzada ya que el radicalismo estaba totalmente derrotado. Al final, el establecimiento de los gobiernos de orientación radical en el Tolima terminaron con la guerra de 1885, en la cual los radicales de Santander se levantaron contra los liberales independientes y fueron derrotados a pesar de que los radicales del Tolima apoyaron a sus partidarios desconociendo al gobierno de Núñez, quien les había exigido participar en la guerra contra los radicales de Santander. Rebelados contra el gobierno central, los radicales del Tolima no pudieron hacer frente a la invasión de la Guardia Nacional al Estado del Tolima, que inició en enero de 1885 bajo las órdenes de Manuel Casabianca y Juan Mateus. Para finales de marzo la guardia ya había logrado su cometido: acabar con el poder radical en el Tolima y dejar en el gobierno del Estado la alianza entre independientes y conservadores, encabezada por el general Manuel Casabianca como presidente militar del Estado gracias al nombramiento proferido por Rafael Núñez.

\section{Consideraciones finales}

Mediante La Estrella del Tolima hemos estudiado uno de los últimos estertores del radicalismo, que a su vez, es el último del Estado Soberano del Tolima. En sus páginas evidenciamos una estrategia desesperada y fallida por promover la unidad

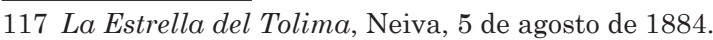


liberal, la cual permite comprobar la relevancia de La Estrella como la tribuna de opinión y defensa radical más activa y prolífica del Tolima, debido a su carácter semioficial y a los cargos oficiales desempeñados por su propietario Alejandro Rojas (presidente del Consejo Municipal) y su redactor principal Miguel María Durán (secretario de gobierno del Tolima). La Estrella fue la tribuna del radicalismo, ya que durante su existencia fue el órgano encargado de difundir el discurso de los dirigentes radicales que gobernaban el Estado, en un periodo de incertidumbre política y evidente debilidad del liberalismo radical, el cual pasó de detentar el poder y excluir a sus adversarios, a ser excluido.

El análisis de La Estrella nos ha permitido establecer que no fue una publicación propiamente regional, sino que gran parte su atención gravitó en torno a Bogotá y los cambios de la política federal. Aunque los redactores del periódico planearon enfocar su atención en los asuntos federales, las transformaciones políticas de la época hicieron que en el camino a las elecciones para presidente del Estado Soberano en 1883 se vieran obligados a participar en asuntos regionales para defenderse de las presiones de sus lectores, y de las acusaciones que les hacían otros liberales, independientes e incluso radicales, quienes afirmaron que La Estrella favorecía al candidato del gobierno del Estado, Gabriel González Gaitán.

La defensa que hicieron los redactores de su "neutralidad" hacia parte de la fallida estrategia de la unidad liberal que se promovió en las páginas de La Estrella, la cual, al fin de cuentas puede catalogarse como un desesperado intento de atraer liberales independientes y negociar con ellos para garantizar la supervivencia de los radicales. La estrategia no fue consecuente con los ataques que se dirigían en los editoriales del periódico a los liberales independientes en el nivel federal, aun cuando tuvieran como fin defender a los liberales independientes con los que negociaban (Zaldúa y Otálora).

La publicación de La Estrella se originó en un momento donde el radicalismo liberal se desmoronaba día a día, y en 
el que se hacía necesaria una tribuna que informara a los lectores liberales y sentara posición ante los ataques que recibían desde publicaciones como La Luz. Los redactores de La Estrella no fijaron los límites de su propio partido al interior del Tolima para intentar atraer a los independientes hacia la unión liberal, siendo este el más grave de sus errores, pues los independientes deseaban desplazar a los radicales del poder tal y como lo habían hecho entre 1876 y 1880 en siete de los nueve estados. Los redactores de La Estrella fueron incapaces de entender que cada espacio que ganaban los independientes era un espacio perdido por los radicales a pesar de los pactos. Aun así, los radicales no perdieron espacios en el gobierno del Estado por vía electoral, motivo por el cual la alianza entre liberales independientes y conservadores apoyó la invasión del gobierno central al Tolima y sepultó definitivamente las aspiraciones de los liberales radicales de La Estrella del Tolima, pues no hubo con ellos unión liberal ni acercamiento, sellando de esta manera en las páginas de La Estrella el último aliento del liberalismo radical del Estado Soberano del Tolima, y marcando el inició de un derrotero para el partido liberal colombiano, el cual, poco a poco sería segregado de la política nacional al ser sencillamente devastados.

\section{Fuentes documentales}

\section{Hemerotecas}

Biblioteca Nacional de Colombia. "Colección de prensa del Tolima siglo XIX». Acceso el 3 de febrero de 2016, http://www. bibliotecanacional.gov.co/content/prensa-tolimense-del-sigloxix.

\section{Periódicos}

Diario de Cundinamarca, Bogotá, 1877.

La Estrella del Tolima, Neiva, 1882-1884.

La República, Neiva, 1882. 


\section{Documentos impresos y manuscritos}

A los habitantes del Estado. Neiva: Imprenta del Estado, 15 de diciembre de 1883.

Castillo, Clodomiro. Rectificaciones a la hoja titulada «la Unión liberal en el Tolima y su programa». Bogotá: Imprenta la Luz, 1884.

Defensa de un Ciudadano. Neiva: Imprenta de A.P. 1883.

«Diligencia de remate». En El centenario de El Tradicionista. Datos para la biografía de Miguel Antonio Caro, de Carlos Valderrama Andrade. Bogotá: Instituto Caro y Cuervo, 1972.

«Ejecución contra la imprenta de 'El Tradicionista' por la suma de $\$ 6.000$ que le fue asignada por empréstito forzoso».En $E l$ centenario de El Tradicionista. Datos para la biografía de Miguel Antonio Caro, de Carlos Valderrama Andrade. Bogotá: Instituto Caro y Cuervo, 1972.

«Expropiación de la imprenta de 'El Tradicionalista'. Memorial». En El centenario de El Tradicionista. Datos para la biografía de Miguel Antonio Caro, de Carlos Valderrama Andrade. Bogotá: Instituto Caro y Cuervo, 1972.

La Unión Liberal en el Tolima y su programa. Neiva: Imprenta de A. Rojas. 10 de enero de 1884.

Memoria que el Secretario de Gobierno del Tolima dirige al presidente del Estado para la Asamblea Legislativa de 1881. Neiva: Imprenta del Estado, 1881.

Rectificaciones a la hoja titulada La Unión Liberal en el Tolima y su programa. Bogotá: La Luz, 1884.

«Remates para el pago de empréstitos forzosos». En El centenario de El Tradicionista. Datos para la biografía de Miguel Antonio Caro, de Carlos Valderrama Andrade. Bogotá: Instituto Caro y Cuervo, 1972.

Un viejo liberal. Neiva: Imprenta de A.P. 16 de octubre de 1883. 


\section{Bibliografía}

Álvarez Gaviria, Jesús María y María Teresa Uribe de Hincapié. Cien años de prensa en Colombia 1840-1940. Catálogo indizado de la prensa existente en la Sala de Periódicos de la Biblioteca Central de la Universidad de Antioquia. Medellín: Editorial Universidad de Antioquia, 2002.

Angarita Somoza, Agustín. Historia del periodismo en el Tolima. t.1. Ibagué: Editorial Tolima, 1970.

Arenas Mendoza, Hugo Andrés. ¿Estado irresponsable o responsable? La responsabilidad patrimonial del Estado colombiano, luego de la Guerra Civil de 1876-1877. Bogotá: Editorial Universidad del Rosario, 2008.

Biblioteca Nacional de Colombia. Catálogo de todos los periódicos que existen desde su fundación hasta el año de 1935. t. 2. Bogotá: Editorial El Gráfico, 1936.

Catálogo publicaciones seriadas siglo XIX, t. 2. Bogotá: Biblioteca Nacional de Colombia / Instituto Colombiano de Cultura, 1995.

Cacua Prada, Antonio. Historia del periodismo colombiano. Bogotá: Fondo Rotatorio Policía Nacional, 1968.

Cuartas Coymat, Álvaro. Tolima Insurgente. Bogotá: Pijao Editores, 1991.

Delpar, Helen. Rojos contra azules. El Partido liberal en la política colombiana 1863-1899. Bogotá: Procultura, 1994.

Higuera, Tarciso. La imprenta en Colombia. Bogotá, Inalpro, 1970.

Mejía Arango, Lázaro. Los Radicales. Historia política del radicalismo del siglo XIX. Bogotá: Universidad Externado de Colombia, 2007.

Moreno, Delimiro. El Huila en el Siglo XIX. Bogotá: Vargas editor, 1994.

. «Periódicos Huilenses». Huila. Órgano de la Academia Huilense de Historia, $\mathrm{n}^{\circ} 31$ (1984): 75-79. 
Otero Muñoz, Gustavo. Historia del periodismo en Colombia. Bogotá: Universidad Sergio Arboleda, 1998.

Ortiz Mesa, Luis Javier. Ganarse el cielo defendiendo la religión guerras civiles en Colombia, 1840-1902. Medellín: Universidad Nacional de Colombia, 2005.

. «los radicales y la guerra civil de 1876-1877». En El radicalismo colombiano del siglo XIX. Editado por Rubén Sierra Mejía. Bogotá: Universidad Nacional de Colombia, 2006: 221-251.

Park, James W. Rafael Núñez and the Politics of Colombian Regionalism. Baton Rouge: University of Louisiana Press, 1985.

Pérez Aguirre, Antonio. Los radicales y la Regeneración. Bogotá: Cromos, 1941.

Pérez Salamanca, Camilo. «Historia del Periodismo». En Manual de Historia del Tolima. V. 1, de Carlos Orlando Pardo Rodríguez, et al. Ibagué: Pijao Editores, 2007, 360-393.

Posada Carbó, Eduardo. «Libertad, libertinaje, tiranía, 1863-1865». En Construcciones impresas. Panfletos, diarios y revistas en la formación de los estados nacionales en América Latina, 18201920. México: Fondo de cultura económica, 2003.

Restrepo Sáenz, José María. Gobernadores y Próceres de Neiva. Bogotá: Editorial ABC, 1951.

Ruíz Martínez, Jean Paul. «Guerra y política en la Neiva decimonónica. Fin de siglo y batalla de Matamundo». En Historia Comprehensiva de Neiva. t. 2, dirigido por Bernardo Tovar Zambrano. Neiva: Alcaldía de Neiva / Academia huilense de historia / Secretaría municipal de cultura y turismo, 2013, 517-536.

Ruíz Martínez, Jean Paul y Cristian Salamanca Arévalo. «Prensa decimonónica de la ciudad de Neiva. Apuntes para su historia». En Historia Comprehensiva de Neiva. t. 2, dirigido por Bernardo Tovar Zambrano. Neiva: Alcaldía de Neiva / Academia huilense de historia / Secretaría municipal de cultura y turismo, 2013,411-443. 
Salamanca Arévalo, Cristian. "La iglesia en Neiva. El papel eclesiástico en la organización socio- política durante el siglo XIX». En Historia Comprehensiva de Neiva. t. 2, dirigido por Bernardo Tovar Zambrano. Neiva: Alcaldía de Neiva / Academia huilense de historia / Secretaría municipal de cultura y turismo, 2013: 173-200.

Salas Ortiz, Camilo Francisco. Historia del periodismo huilense: la prensa escrita. Neiva: Instituto huilense de cultura, 1994.

. «Trayectoria del periodismo huilense». En Historia general de Huila. t. 3, dirigido por Bernardo Tovar Zambrano. Neiva: Instituto huilense de cultura / Fondo de autores huilenses / Gobernación del dpto. del Huila / Academia Huilense, 2005: 97-146.

Salas Vargas, Reynel. «Relación de periódicos editados en el departamento del Huila. Existentes en la Hemeroteca Manuel del Socorro Rodríguez de la Biblioteca Nacional». Huila. Órgano de la Academia Huilense de Historia, no 37 (1987): 85-87.

Sánchez Ramírez, Francisco. «Periodismo en el Huila». Huila. Órgano de la Academia Huilense de Historia, $\mathrm{n}^{\circ} 31$ (1984): 68-74.

Santamaría Granda, Magdalena. Historia y desarrollo de la prensa en Ibagué. Bogotá, 2001.

Smith, David Eugene. «Lazare Nicholas Marguerite Carnot». The Scientific Monthly 37, $\mathrm{n}^{\circ} 2$ (1933): 188-189.

Trilleras Roa, Álvaro. Del linotipo al satélite. Los medios de comunicación y el periodismo en el Huila. Neiva: Impresos Litosol, 2005

\section{Citar este artículo:}

Ruíz Martínez, Jean Paul y Cristian Salamanca Arévalo, «La Estrella del Tolima, 1882-1884. Elúltimo aliento del liberalismo radical en Neiva». Historia Y MEMORIA, n 13 (2016): 215256. DOI: http://dx.doi.org/10.19053/20275137.5205 